\title{
Remedial Prospective of Hippophae rhamnoides Linn. (Sea Buckthorn)
}

\author{
Chirag A. Patel, ${ }^{1}$ Kalyani Divakar, ${ }^{2}$ Devdas Santani, ${ }^{3}$ \\ Himanshu K. Solanki, ${ }^{4}$ and Jalaram H. Thakkar ${ }^{1}$ \\ ${ }^{1}$ Department of Pharmacology, SSR College of Pharmacy, Sayli-Silvassa Road, Sayli, UT oF Dadra \& Nagar Haveli 396230, India \\ ${ }^{2}$ Department of Pharmacology, Acharya \& B. M. Reddy College of Pharmacy, Chikkabanavara, Bangalore 560090, India \\ ${ }^{3}$ Department of Pharmacology, Rofel Shri G.M. Bilakhia College of Pharmacy, Namdha Road, Vapi 396191, India \\ ${ }^{4}$ Department of Pharmaceutics, SSR College of Pharmacy, Sayli-Silvassa Road, Sayli, UT oF Dadra \& Nagar Haveli 396230, India
}

Correspondence should be addressed to Chirag A. Patel, patel_chirag1787@yahoo.co.in

Received 18 November 2011; Accepted 28 December 2011

Academic Editors: K. Cimanga, J. C. Laguna, and M. Tohda

Copyright (๑) 2012 Chirag A. Patel et al. This is an open access article distributed under the Creative Commons Attribution License, which permits unrestricted use, distribution, and reproduction in any medium, provided the original work is properly cited.

Sea buckthorn (Hippophae rhamnoides L.) constitutes thorny nitrogen fixing deciduous shrub. Sea buckthorn(SBT) is primarily valued for its very rich vitamins $\mathrm{A}, \mathrm{B}_{1}, \mathrm{~B}_{12}, \mathrm{C}, \mathrm{E}, \mathrm{K}$, and P; flavonoids, lycopene, carotenoids, and phytosterols. and therapeutically important since it is rich with potent antioxidants. Scientifically evaluated pharmacological actions of SBT are like inflammation inhibited by reduced permeability, loss of follicular aggregation of lymphocytes from the inflamed synovium and suppress lymphocyte proliferation. SBT-reduced recurrence of angina, ischemic electrocardiogram which might be due to decreased myocardial oxygen consumption and inhibition of platelet aggregation induced by collagen. SBT can kill both cancer cells of S180, P388, SGC7901 and lymphatic leukemia (L1200). The antiulcer activity may be related to reduce gastric empty time, inhibiting proteolytic activity and promoting wound reparation processes of mucosa. SBT exerts antihypertensive effect in part by blocking angiotensin-2 receptor on cell surface. SBT decreased the level of stress hormones and enhanced hypoxic tolerance in animals indicating its anti-stress, adaptogenic activity. A lot of research work is still needed to find cellular and molecular mechanisms of these activities and also yet to be explored for its activity in osteoporosis, hemorrhage, cataract, urinary stone, acne, psoriasis, polyneuritis, cheilosis, glossities, baldness, anti-obesity, gout, and chronic prostitis.

\section{Introduction}

Sea buckthorn (Hippophae rhamnoides L., Elaeagnaceae) constitutes a thorny nitrogen fixing deciduous shrub which cultivated various parts of the world for its nutritional and medicinal values [1]. A Sea buckthorn fruits (Figure 1), seed (Figure 2) and other parts is primarily valued for its very rich vitamins $\mathrm{A}, \mathrm{B} 1, \mathrm{~B} 12, \mathrm{C}, \mathrm{E}, \mathrm{K}$ and $\mathrm{P}$; flavonoids, lycopene, carotenoids, and phytosterols. Therapeutically important because it is rich with potent antioxidants [2-4]. These compounds are of interest not only from the chemical point of view, but also because many of them possess biological and therapeutic activities including antioxidant, cardiovascular, cancer therapy, healing, anti-inflammation, antiradiation effect, treatment of gastrointestinal ulcers, as a liver protective agent, antioxidant, platelet aggregation, and immunomodulator [5]. Because of these effects, $H$. rhamnoides L. containing bioactive compounds is often used in traditional medicine. See Table 1 for Constituents of Sea buckthorn Fruit.

\section{Manufacture of Sea Buckthorn Products}

Figure 3 is a diagram of a processing method that can be used to separate useful components of the berries, yielding the key products of juice, dried fruit nutrients, and oil from the seeds and pulp; residues can be utilized as valuable animal feed. New technologies, involving supercritical carbon dioxide extraction, are now being used in China to efficiently produce the oil products. 
TABle 1: Constituents of Sea buckthorn Fruit [2].

\begin{tabular}{|c|c|c|}
\hline Sr. no. & Constituents of sea buckthorn fruit (Per 100 gra & h berries) \\
\hline 1 & $\begin{array}{l}\text { The main unsaturated fatty acids are oleic acid (omega-9), palmitoleic acid } \\
\text { (omega-7), palmitic acid and linoleic acid (omega-6), and linolenic acid } \\
\text { (omega-3); there are also saturated oils and sterols (mainly } \beta \text {-sitosterol) }\end{array}$ & $\begin{array}{l}6-11 \%(3-5 \% \text { in fruit pulp, } 8-18 \% \\
\text { in seed) fatty acid composition } \backslash \text { and } \\
\text { total oil content vary with subspecies }\end{array}$ \\
\hline 2 & Vitamin C & $28-310 \mathrm{mg}$ (typical amount: $600 \mathrm{mg}$ ) \\
\hline 3 & $\begin{array}{l}\text { Carotenoids, including beta carotene, lycopene, and zeaxanthin; these } \\
\text { contribute to the yellow-orange-red colors of the fruit }\end{array}$ & $32-45 \mathrm{mg}$ fatty acids (oils) \\
\hline 4 & Vitamin E (mixed tocopherols) & Up to $180 \mathrm{mg}$ (equal to about $270 \mathrm{IU}$ ) \\
\hline 5 & Folic acid & Up to $80 \mathrm{mcg}$ \\
\hline 6 & $\begin{array}{l}\text { Organic acids for example, quinic acid, malic acid; ingredients similar to } \\
\text { those are found in cranberries }\end{array}$ & $\begin{array}{l}\text { Quantity not determined expressed } \\
\text { juice has } \mathrm{pH} \text { of } 2.7-3.3\end{array}$ \\
\hline 7 & Flavonoids (e.g., mainly isorhamnetin, quercetin glycosides, and kaempferol) & $50-500 \mathrm{mg}(0.05 \%$ to $0.5 \%)$ \\
\hline
\end{tabular}



FIgURE 1: Sea buckthorn fruits.

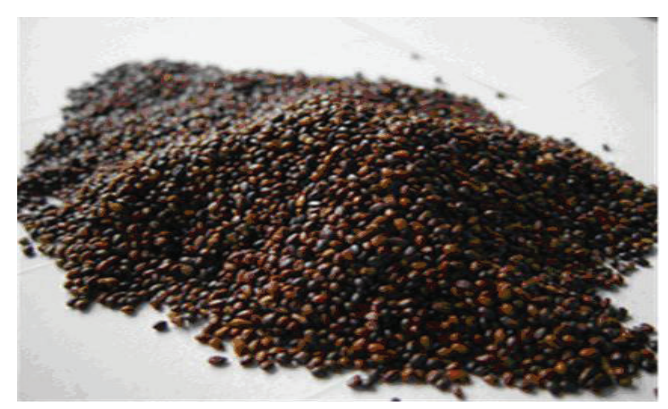

FIgURE 2: Sea buckthorn seeds.

\section{Pharmacological Account of Sea Buckthorn with Recommendation Mechanism of Action}

3.1. Platelet Aggregation. Cheng et al. suggest that total flavonoids of $H$. rhamnoides $\mathrm{L}$. (TFH) may suppress platelet aggregation induced by collagen, probably due to the inhibition of tyrosine kinase activity. It has been reported that collagen receptor stimulation leads to tyrosine phosphorylation of Syk (Spleen tyrosine kinase) or Src (proto-oncogene encoding a tyrosine kinase), followed by phospholipase Cgamma 2 activation. Tyrosine kinase activation increases intracellular calcium and activates phospholipids A2 (PLA2), followed by synthesis of arachidonic acid from phospholipids in plasma membrane [5]. The rate of aggregation reaction ( $\%$ aggregation/min) was also reduced by SBT supplementation [6].

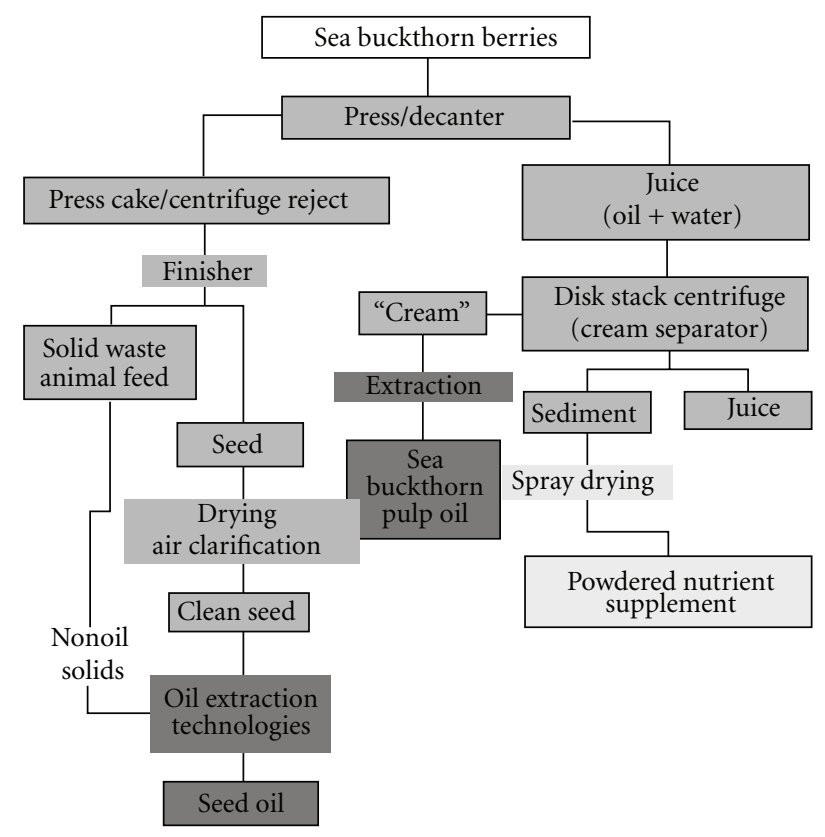

FIGURE 3: Flow diagram of manufacturing of product from sea buckthorn.

3.2. Antioxidant and Antibacterial. The Sea buckthorn leaf extract exhibited inhibitory effect on the chromium-induced effect of plasma MDA levels. It also restored the intracellular antioxidants such as reduced glutathione (GSH) and Glutathione peroxidase (GPx) and also exhibited inhibition of ROS/free radical production [7, 8]. It also showed maintenance of mitochondrial and nuclear integrity as well as restoring the phagocytosis by macrophages [9]. The extract also protected animals significantly from the hepatotoxicity by decreasing creatine phosphokinase (CPK), serum glutamate oxaloacetate transferase (SGOT), and serum glutamate pyruvate transferase (SGPT) level compared to the chromium-treated animals [10].

3.3. Antiulcer. The antiulcer action of sea buckthorn oils related to an increased in the hydrophobicity of the mucosal surface, retarded the gastric emptying [11], inhibited lipid 
peroxidation in gastric mucosa, accelerated of the mucosal repair [12], inhibited proteolytic activity in gastric liquid, promoted the wound reparation processes of mucosa and prevent mucosa damage [13].

3.4. Anti-Inflammatory. Lymphocyte proliferation decreased by SBT clearly indicates inhibition of T-cell activation [14]. Due to the presence of some mitogens in SBT, it stimulated lymphocyte proliferation [15]. SBT had reductive effect on C-reactive protein, a marker of inflammation and a risk factor for cardiovascular diseases [16]. It was possible that inhibition of nitric oxide (NO) production by SBT leaf extract could be due to inhibition of transcription of the iNOS gene which was quite evident at translation level on probing with Moab against iNOS. The onset of the NO production cascade induced by lipopolysaccharides in macrophages required a number of steps such as the activation of nuclear factor (NF)-kh and subsequent iNOS mRNA expression [17].

3.5. Anticancer. H. rhamnoides L., with major constituents includes, quercetin-induced apoptosis in cancer cells, such as HT- 29 human colon cancer cells, HL-60, and K562 human leukemia cells, baicalin-induced apoptosis in prostate cancer cells. Sea buckthorn juice not only inhibits growth of the human gastric carcinoma (SGC7901) and lymphatic leukemia (L1200) but kills both S180 and P388 cancer cells [18]. SBT juice decreased genotoxic effect of cisplatin on somatic and germ cell of mice [19]. SBT fruit is able to decrease carcinogen-induced stomach and skin tumorigenesis, which might involve upregulation of phase II and antioxidant enzymes as well as DNA-binding activity of IRF-1, a known antioncogenic transcription factor causing growth suppression and apoptosis induction for its anticancer effect [20]. SBT can be anticipated that the antimutagenic activity via antioxidative mechanism [21]. Sea buckthorn juice can block the endogenous formation of N-nitroso compounds more effectively than ascorbic acid and thereby prevent tumor production [22-24].

3.6. Hepatic Disease. Sea buckthorn could reduce the serum levels of laminin, hyaluronic acid, total bile acid (TBA), and collagen types III and IV in patients with liver cirrhosis, demonstrating that it may restrain the synthesis of collagen and other components of extracellular matrix [25]. SBT also fixes vitamin A and RAR contents of hepatic stellate cells (HSCs), so as to keep HSCs in a quiescent status and to prevent progression of liver fibrosis [26]. SBT has apparent hepatoprotective properties and alleviating liver injury caused by carbon tetrachloride [27].

3.7. Cardiac Effect. TFH could improve the mechanocardiography and the ischemic electrocardiogram. SBT increased the internal pressure peak of the left ventriculus and its maximum rate of change (dp/dtmax) distinctly, the time from the left ventricle starting a contraction to the occurrence of a $\mathrm{dp} / \mathrm{dtmax}$ was shortened 4 distinctly, the diastolic pressure of the left ventricle and the left ventricular pressure of the isovolumetric relaxation phase diminished, and cardiac output, cardiac index, heart stroke index, and left ventricular power index of the myocardium increased [28]. Further research showed that TFH could strengthen the contractility of the extracorporeal papillary muscles of guinea pigs. TFH could prolong the time of ventricular fibrillation, postpone the atrioventricular conduction, lower the heart rate, and attenuate the myocardial contractility [29].

3.8. Antihypertensive Effect. In view of the previous researches that TFH is effective in decreasing the concentration of intracellular-free calcium induced by angiotensin-2 in vascular smooth muscle cells by blocking receptor-operated calcium channels, it is possible to conclude that TFH exerts its antihypertensive effect, in part, by blocking angiotensin2 receptor on cell surface and thus arrest downstream signal pathway. In sum, hypertension, hyperinsulinemia, dyslipidemia, and activated angiotensin- 2 provoked by the high-sucrose diet can be ameliorated or modulated by total flavones purified from seed residues of Hippophae rhamnoides L., and the best effect was shown at the dose of $150 \mathrm{mg} / \mathrm{kg} /$ day [30].

3.9. Healing. SBT promotes cutaneous wound healing [31], burns wound healing [32], and dermals wound healing [33] by increasing antioxidant and protecting again sulfur dioxide [34] and mustard-gas-induced injury [35]. TFH enhanced mechanical strength of healing tendons and can thus be credited to enhance collagen deposition and collagen maturation with an altered cytokine profile in the wound. TFH may increase TGF $\beta 1$ and fibrogenic cytokine that stimulates collagen production in tendons and decreases COX-2 in the healing tendons $[36,37]$. Sea buckthorn seed oil significantly attenuated hypoxia-induced oxidative stress, maintaind blood-brain barrier membrane integrity, restricted the rise in plasma catecholamine, and significantly enhanced the hypoxic tolerance in experimental animals [38]. SBT seed oil also decrease the level of stress hormones and enhances hypoxic tolerance in animals exposed to hypoxia indicating its antistress and adaptogenic activity against hypoxia [39].

3.10. Radiation. The radio protective effect generated by SBT at molecular level in terms of free radical scavenging as studied through in-vitro studies could explain the cellular survival, proliferation enhancement, immunostimulation, and ultimately the whole body survival [40]. Maintenance of chromatin organization, induction of hypoxia, protects hydrogen atom donation, free radical scavenging [41], and blocking of cell cycle at G2-M phase by interfering with topoisomerase-I activity and mitochondrial and genomic DNA from radiation seem to contribute towards the radio protective efficacy of SBT [42].

3.11. Atopic Dermatitis. Sea buckthorn seed oil treatment increased the level of a-linolenic, linoleic, and eicosapentaenoic acids, whereas pulp oil supplementation $\beta$-Sitosterol 
TABLE 2: List of available sea buckthorn market products.

\begin{tabular}{|c|c|}
\hline Product name & Manufacturer name \\
\hline Sea buckthorn oil softgel & Fraken biochem co., ltd. [Shandong, China] \\
\hline Fructus hippophae extract & Rui heng industry co., ltd. [China] \\
\hline Sea buckthorn pulp oil & $\begin{array}{l}\text { Inner mongolia yuhangren hi-tech industrial co., ltd. [province: Inner Mongolia, } \\
\text { China] }\end{array}$ \\
\hline Sea buckthorn seed oil & Hebei shenxing sea buckthorn health products co., ltd. [China] \\
\hline Immune-enhancing ingredients & Shanghai brightol international co., ltd. [province:shanghai, China] \\
\hline Fish oil softgel capsule \& lecithin softgel capsule & Qingdao dacon trading co., ltd. [province:Shandong, China] \\
\hline Sea buckthorn berry oil sea buckthorn seeds & Beijing powdery food co., ltd. [province:Beijing, China] \\
\hline Oil capsule (y-o-04) & Youchain group co., ltd. [province:Hebei, China] \\
\hline Shenxing sea buckthorn xinzhian oral liquid & Hebei shenxing sea buckthorn health products co., ltd. [province:Hebei, China] \\
\hline Organic sea buckthorn fruit oil soft capsule & Hebei shenxing sea buckthorn health products co., ltd. [province:Hebei, China] \\
\hline Organic sea buckthorn berry/fruit powder & Hebei shenxing sea buckthorn pharmaceutical co., ltd. [province:Hebei, China] \\
\hline Sea buckthorn fruit oil capsules-1 & Jinan sea buckthorn trade co., ltd. [province:Shandong, China] \\
\hline $\begin{array}{l}\text { Jinan sea buckthorn trade co., ltd. [province: } \\
\text { Shandong, China] }\end{array}$ & Jinan sea buckthorn trade co., ltd. [province:Shandong, China] \\
\hline Seabuckthorm seed oil capsule & Wutai mountain sea buckthorn co., ltd. [province:Shanxi, China] \\
\hline Sea buckthorn berry powder & Shijiazhuang yiling pharmaceutical co., ltd. [province:Beijing, China] \\
\hline Sea buckthorn powder & Beijing powdery food co., ltd. [province:Beijing, China] \\
\hline Spirulina & Dechen nutrachem co., ltd. [province:Shandong, China] \\
\hline Sea buckthorn seed oil (flu-s003) & Inner mongolia prosperous earth trade co., ltd. [province:Inner Mongolia, China] \\
\hline Sea buckthorn seed oil (flu-s004) & Inner mongolia prosperous earth trade co., ltd. [province:Inner Mongolia, China] \\
\hline Sea buckthorn oil & $\begin{array}{l}\text { Guangzhou honsea sunshine bio science \& technology co., ltd. [province:Guangdong, } \\
\text { China] }\end{array}$ \\
\hline Sea buckthorn seed oil capsule (hy-08003) & Beijing huiyuan group youyu co., ltd. [province:Shanxi, China] \\
\hline Sea buckthorn galic softgel (psg) & Perfect (China) co., ltd. [province:Guangdong, China] \\
\hline Sea buckthorn fruit oil & Wutai mountain sea buckthorn co., ltd. [province:Shanxi, China] \\
\hline Fruit juice concentrate & Heilongjiang provincial hongri trading co., ltd. [province:Heilongjiang, China] \\
\hline Sea buckthorn effervescent tablets & Nanjing union biotech co., ltd. [province:Jiangsu, China] \\
\hline Frozen sea buckthorn berry & Conseco sea buckthorn co., ltd. [province:Beijing, China] \\
\hline Digestive support herbal candy & Candy manufacturer inc. [province:Guangdong, China] \\
\hline Capsules of nutrient products & Shanghai honghao chemicals co. Ltd. [province:Shanghai, China] \\
\hline Menova heyeqianzi slimming herbs capsule & panda international trade co., limited [province:Hong Kong, China] \\
\hline Softgel capsule [2010-08-17] & Sunrise nutrachem group [province:Shandong, China] \\
\hline Skin whitening product & Chifeng wedge pharmaceutical co., ltd. [province:Inner Mongolia, China] \\
\hline
\end{tabular}

and $\beta$-carotene in the oils may also have effected on the symptoms of Atopic dermatitis [43].

3.12. Anti-Atherogenic and Hypoglycemic Activity. Atherogenic index (AI) was significantly reduced and acetylcholineinduced vasorelaxation was markedly impaired which could be restored to control values in SBT seed oil treated normally and hypercholesterolemic animals [44]. SBT decreases blood glucose and lipid in normal mice, and effect of SBT on glycometabolism may be related to the control of gluconeogenesis [45].

\section{Pharmacological Effects of Sea Buckthorn yet to Be Explored in Relation with Other Diseases}

SBT is a traditional herbal medicine, which has long used many condition like relieving cough, diarrhea, aiding digestion, invigorating blood circulation alleviating pain, treating colitis and enterocolitis since ancient time because it is rich of antioxidant. Juice, syrup, and oil of the fruits have been used in disantheria, osteoporosis, hemorrhage, cataract, urinary stone, acne, psoriasis, sterility, polyneuritis, cheilosis, 
glossitis, baldness, analgesic, benign prostatic hypertrophy, antiobesity, gout, and chronic prostitisas a metabolism regulator in traditional medicine [46].

\section{Sea Buckthorn Market Products [47]}

See Table 2 .

\section{Conclusion}

SBT has high-nutritional and medicinal values due to its very rich antioxidant property. It is a widely used plant in traditional medicine for various clinical conditions. Scientifically evaluated pharmacological effects of it are like antiulcerogenic effect, in vitro and in vivo antioxidant effects, cardiac disease, antiatherogenic effect, radio protective effects, beneficial effects on experimental injury and clinical diseases of the liver, nad inhibition of platelet aggregation. Lot of research work is still needed to find cellular and molecular mechanisms of these activities.

\section{References}

[1] Sea buckthorn Factsheet, Al Oliver, pp. 1-4, May 2001.

[2] Z. Alam, "Chemical and nutritional constituents of sea buckthorn juice," Pakistan Journal of Nutrition, vol. 3, no. 2, pp. 99-106, 2004.

[3] Y. Zhao and F. Wu, "Sea buckthorn flavonoids and their medical value," Hippophae, vol. 10, no. 1, pp. 39-41, 1997.

[4] Z. Alam, "Important therapeutic uses of sea buckthorn (Hippophae): a review," Journal of Biological Sciences, vol. 4, no. 5, pp. 687-693, 2004.

[5] J. Cheng, K. Kondo, Y. Suzuki, Y. Ikeda, X. Meng, and K. Umemura, "Inhibitory effects of total flavones of Hippophae rhamnoides $\mathrm{L}$ on thrombosis in mouse femoral artery and in vitro platelet aggregation," Life Sciences, vol. 72, no. 20, pp. 2263-2271, 2003.

[6] A. K. Johansson, H. Korte, B. Yang, J. C. Stanley, and H. P. Kallio, "Sea buckthorn berry oil inhibits platelet aggregation," Journal of Nutritional Biochemistry, vol. 11, no. 10, pp. 491495, 2000.

[7] S. Narayanan, D. Ruma, B. Gitika et al., "Antioxidant activities of seabuckthorn (Hippophae rhamnoides) during hypoxia induced oxidative stress in glial cells," Molecular and Cellular Biochemistry, vol. 278, no. 1-2, pp. 9-14, 2005.

[8] S. Geetha, M. S. Ram, S. S. Mongia, V. Singh, G. Ilavazhagan, and R. C. Sawhney, "Evaluation of antioxidant activity of leaf extract of Seabuckthorn (Hippophae rhamnoides L.) on chromium(VI) induced oxidative stress in albino rats," Journal of Ethnopharmacology, vol. 87, no. 2-3, pp. 247-251, 2003.

[9] S. Geetha, M. Sai Ram, V. Singh, G. Ilavazhagan, and R. C. Sawhney, "Effect of seabuckthorn on sodium nitroprussideinduced cytotoxicity in murine macrophages," Biomedicine and Pharmacotherapy, vol. 56, no. 9, pp. 463-467, 2002.

[10] A. S. Chauhan, P. S. Negi, and R. S. Ramteke, "Antioxidant and antibacterial activities of aqueous extract of Seabuckthorn (Hippophae rhamnoides) seeds," Fitoterapia, vol. 78, no. 7-8, pp. 590-592, 2007.

[11] J. Xing, B. Yang, Y. Dong, B. Wang, J. Wang, and H. P. Kallio, "Effects of sea buckthorn (Hippophae rhamnoides L.) seed and pulp oils on experimental models of gastric ulcer in rats," Fitoterapia, vol. 73, no. 7-8, pp. 644-650, 2002.

[12] X. Xu, B. Xie, S. Pan, L. Liu, Y. Wang, and C. Chen, "Effects of sea buckthorn procyanidins on healing of acetic acid-induced lesions in the rat stomach," Asia Pacific Journal of Clinical Nutrition, vol. 16, no. 1, pp. 234-238, 2007.

[13] S. Halis, E. B. Mehmet, K. Mehmet, A. Fatih, K. Ahmet, and G. Akçahan, "The effects of Hippophae rhamnoides L. extract on ethanol-induced gastric lesion and gastric tissue glutathione level in rats: a comparative study with melatonin and omeprazole," Indian Journal of Pharmacology, vol. 33, no. 2, pp. 77-81, 2001.

[14] L. Ganju, Y. Padwada, R. Singha et al., "Anti-inflammatory activity of Sea buckthorn (Hippophae rhamnoides) leaves," International Immunopharmacology, vol. 5, pp. 1675-1684, 2005.

[15] S. Geetha, M. SaiRam, V. Singh, G. Ilavazhagan, and R. C. Sawhney, "Anti-oxidant and immunomodulatory properties of Sea buckthorn (Hippophae rhamnoides) —an in vitro study," Journal of Ethnopharmacology, vol. 79, pp. 373-378, 2002.

[16] P. S. Larmo, J. A. Alin, E. K. Salminen, H. P. Kallio, and R. L. Tahvonen, "Effects of Sea buckthorn berries on infections and inflammation," Journal of Clinical Nutrition, vol. 27, pp. 1-3, 2007.

[17] Y. Padwad, L. Ganju, and M. Jain, "Effect of leaf extract of Sea buckthorn on lipopolysaccharide induced inflammatory response in murine macrophages," International Immunopharmacology, vol. 6, pp. 646-652, 2006.

[18] B. S. Teng, Y. H. Lu, Z. T. Wang, X. Y. Tao, and D. Z. Wei, "In vitro anti-tumor activity of isorhamnetin isolated from Hippophae rhamnoides L. against BEL-7402 cells," Pharmacological Research, vol. 54, no. 3, pp. 186-194, 2006.

[19] N. Armen and M. Rafael, "Sea-buckthorn juice protects mice against genotoxic action of cisplatin," Experimental Oncology, vol. 26, no. 2, pp. 153-155, 2004.

[20] B. Padmavathi, M. Upreti, V. Singh, A. R. Rao, R. P. Singh, and P. C. Rath, "Chemoprevention by Hippophae rhamnoides: effects on tumorigenesis, phase II and antioxidant enzymes, and IRF-1 transcription factor," Nutrition and Cancer, vol. 51, no. 1, pp. 59-67, 2005.

[21] A. Bhatia, S. Arora, A. Nagpal, B. Singh, and P. S. Ahuja, "Evaluation of in vitro antimutagenic activity of Sea buckthorn (Hippophae rhamnoides Linn.) in Ames assay," Journal of Chinese Clinical Medicine, vol. 2, no. 8, 2007.

[22] Y. Li and H. Liu, "Prevention of tumour production in rats fed aminopyrine plus nitrite by sea buckthorn juice," IARC Scientific Publications, no. 105, pp. 568-570, 1991.

[23] Z. Zhang and D. Qiu, "Anti-cancer studies from Russia," Hippophae, vol. 8, no. 4, pp. 38-40, 1995.

[24] L. Ren, J. Yang et al., "Observation: anti-mutation and anti immune-suppresser properties from sea buckthorn seed oil," Hippophae, vol. 5, 1992.

[25] Z. L. Gao, X. H. Gu, F. T. Cheng, and F. H. Jiang, "Effect of Sea buckthorn on liver fibrosis: a clinical study," World Journal of Gastroenterology, vol. 9, no. 7, pp. 1615-1617, 2003.

[26] G. M. Lipkan and O. A. Oliünyk, "Hepatoprotective effect of the sea buckthorn-and-pinks oil," Lik Sprava, no. 6, pp. 96-99, 2000.

[27] C. Liu, J. Xu, C. Q. Ye, and C. Huang, "Effects and comparison of seed oil and sarcocarp oil of Hippophae rhamnoides on rats with experimental hepatocirrhosis," Zhongguo Zhongyao Zazhi, vol. 31, no. 13, pp. 1100-1102, 2006. 
[28] M. Xu, X. Sun, and J. Cui, "The medicinal research and development of Sea buckthorn".

[29] B. Wang, Y. Feng, Y. Yu, H. Zhang, and R. Zhu, "Effects of total flavones of Hippophae Rhamnoids L (Sea buckthorn) on Cardiac Function and Hemodynamic in Healthy Human Subjects," Rich Nature Nutroceutical Laboratories.

[30] X. Pang, J. Zhao, W. Zhang et al., "Antihypertensive effect of total flavones extracted from seed residues of Hippophae rhamnoides L. in sucrose-fed rats," Journal of Ethnopharmacology, vol. 117, no. 2, pp. 325-331, 2008.

[31] A. Gupta, R. Kumar, K. Pal, P. K. Banerjee, and R. C. Sawhney, "A preclinical study of the effects of seabuckthorn (Hippophae rhamnoides L.) leaf extract on cutaneous wound healing in albino rats," International Journal of Lower Extremity Wounds, vol. 4, no. 2, pp. 88-92, 2005.

[32] R. Vijayaraghavan, A. Gautam, O. Kumar et al., "Protective effect of ethanolic and water extracts of sea buckthorn (Hippophae rhamnoides L.) against the toxic effects of mustard gas," Indian Journal of Experimental Biology, vol. 44, no. 10, pp. 821-831, 2006.

[33] A. Ruan, H. Min, Z. Meng, and Z. Lü, "Protective effects of seabuckthorn seed oil on mouse injury induced by sulfur dioxide inhalation," Inhalation Toxicology, vol. 15, no. 10, pp. 1053-1058, 2003.

[34] Z. Y. Wang, X. L. Luo, and C. P. He, "Management of burn wounds with Hippophae rhamnoides oil," Journal of Southern Medical University, vol. 26, no. 1, pp. 124-125, 2006.

[35] A. Gupta, R. Kumar, K. Pal, V. Singh, P. K. Banerjee, and R. C. Sawhney, "Influence of sea buckthorn (Hippophae rhamnoides L.) flavone on dermal wound healing in rats," Molecular and Cellular Biochemistry, vol. 290, no. 1-2, pp. 193-198, 2006.

[36] N. K. Upadhyay, R. Kumar, S. K. Mandotra et al., "Safety and healing efficacy of Sea buckthorn (Hippophae rhamnoides L.) seed oil on burn wounds in rats," Food and Chemical Toxicology, vol. 47, no. 6, pp. 1146-1153, 2009.

[37] S. C. Fu, C. W. C. Hui, L. C. Li et al., "Total flavones of Hippophae rhamnoides promotes early restoration of ultimate stress of healing patellar tendon in a rat model," Medical Engineering and Physics, vol. 27, no. 4, pp. 313-321, 2005.

[38] J. Purushothaman, G. Suryakumar, D. Shukla et al., "Modulatory effects of seabuckthorn (Hippophae rhamnoides L.) in hypobaric hypoxia induced cerebral vascular injury," Brain Research Bulletin, vol. 77, no. 5, pp. 246-252, 2008.

[39] A. C. Varshney, "Sea buckthorn (Hippphae sp.) for soft tissue repair in animal".

[40] H. C. Goel, J. Prasad, S. Singh, R. K. Sagar, I. Prem Kumar, and A. K. Sinha, "Radioprotection by a herbal preparation of Hippophae rhamnoides, RH-3, against whole body lethal irradiation in mice," Phytomedicine, vol. 9, no. 1, pp. 15-25, 2002.

[41] S. K. Shukla, P. Chaudhary, I. P. Kumar et al., "Protection from radiation-induced mitochondrial and genomic DNA damage by an extract of Hippophae rhamnoides," Environmental and Molecular Mutagenesis, vol. 47, no. 9, pp. 647-656, 2006.

[42] H. C. Goel, I. P. Kumar, N. Samanta, and S. V. S. Rana, "Induction of DNA-protein cross-links by Hippophae rhamnoides: implications in radioprotections and cytotoxicity," Molecular and Cellular Biochemistry, vol. 245, no. 1-2, pp. 57-67, 2003.

[43] B. Yang, K. O. Kalimo, R. L. Tahvonen, L. M. Mattila, J. K. Katajisto, and H. P. Kallio, "Effect of dietary supplementation with sea buckthorn (Hippophae rhamnoides) seed and pulp oils on the fatty acid composition of skin glycerophospholipids of patients with atopic dermatitis," Journal of Nutritional Biochemistry, vol. 10, no. 11, pp. 622-630, 2000.
[44] M. Basu, R. Prasad, P. Jayamurthy, K. Pal, C. Arumughan, and R. C. Sawhney, "Anti-atherogenic effects of seabuckthorn (Hippophaea rhamnoides) seed oil," Phytomedicine, vol. 14, no. 11, pp. 770-777, 2007.

[45] Q. Cao, W. Qu, Y. Deng, Z. Zhang, W. Niu, and Y. Pan, "Effect of flavonoids from the seed and fruit residue of Hippophae rhamnoides L. on glycometabolism in mice," Journal of Chinese Medicinal Materials, vol. 26, no. 10, pp. 735-737, 2003.

[46] V. B. Guliyev, M. Gul, and A. Yildirim, "Hippophae rhamnoides L.: chromatographic methods to determine chemical composition, use in traditional medicine and pharmacological effects," Journal of Chromatography B, vol. 812, no. 1-2, pp. 291-307, 2004.

[47] http://www.taoofherbs.com/info/seabuckthorn/seabuckprod asp. 

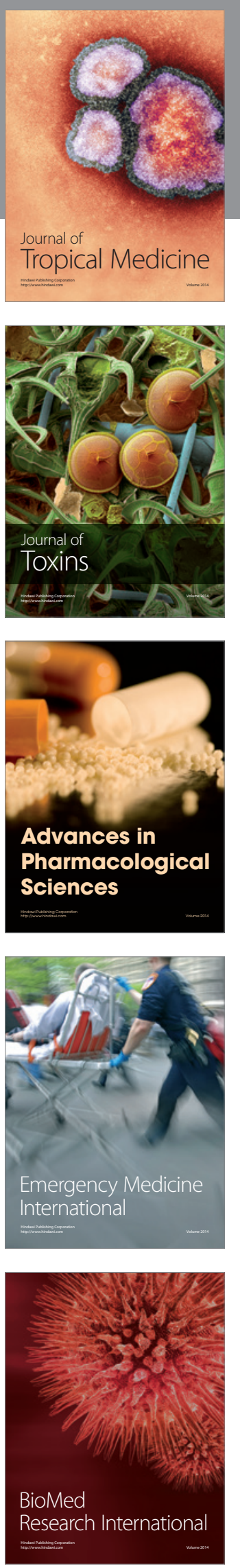
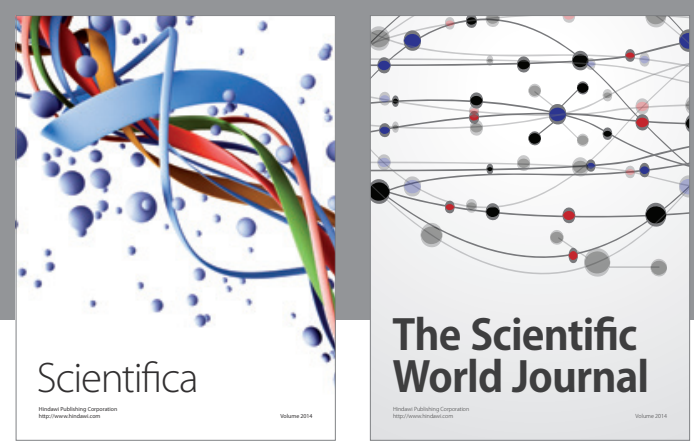

The Scientific World Journal
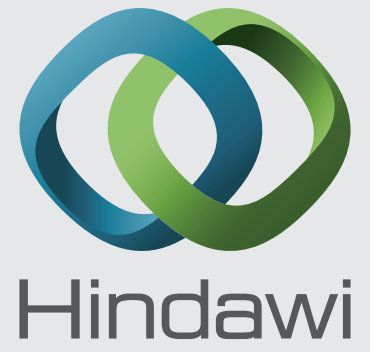

Submit your manuscripts at

http://www.hindawi.com
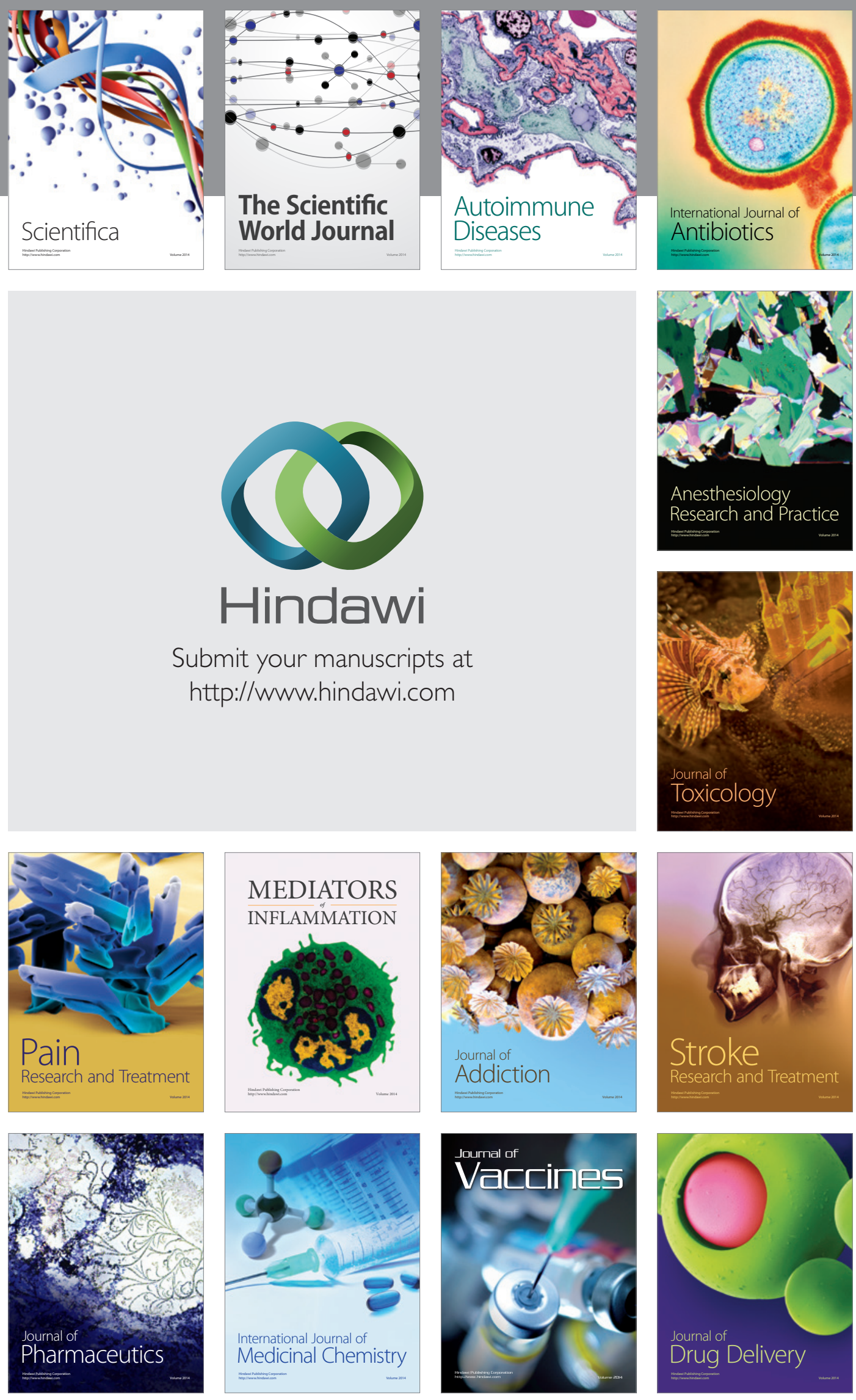